\title{
Online gaming and gaming disorder: more than just a trivial pursuit
}

\author{
David Columb $^{1, *}$ (1) , Mark D. Griffiths ${ }^{2}$ and Colin $\mathrm{O}^{\prime} \mathrm{Gara}^{1,3}$ \\ ${ }^{1}$ Addiction Department, St John of God Hospital, Stillorgan, Dublin, Ireland \\ ${ }^{2}$ Nottingham Trent University, Nottingham, UK \\ ${ }^{3}$ UCD School of Medicine and Medical Specialties, University College Dublin, Dublin, Ireland
}

\begin{abstract}
Gaming disorder is set to be included in the International Statistical Classification of Diseases and Related Health Problems alongside other behavioural addictions (gambling disorder) and substance-related addictions. Given the popularity of online gaming, this is set to become an increasingly common presentation to general mental health professionals, addiction specialists, and general practitioners. This article briefly examines online gaming and describes the characteristics of gaming disorder. Some features of online gaming that have addictive potential and similarities to other addictive behaviours such as gambling disorder are discussed. Finally, the article examines treatment options available for gaming disorder and treatment going forward from an Irish perspective.
\end{abstract}

Received 21 November 2018; Revised 01 July 2019; Accepted 01 July 2019; First published online 01 August 2019

Key words: Gaming disorder, online gaming, esports, micro-transactions, loot boxes, behavioural addiction, Ireland.

\section{Introduction}

The introduction of gambling disorder in the latest (fifth) edition of the American Psychiatric Association's (2013) Diagnostic and Statistical Manual of Mental Disorders (DSM-5) represented a paradigm shift in how addiction is viewed. Gambling disorder was the first behavioural addiction to be officially recognised alongside alcohol and other substance-based addictions in terms of clinical and scientific importance. Behavioural addictions have been described as syndromes analogous to substance addiction but with a behavioural focus rather than the ingestion of a psychoactive substance (Grant et al. 2010).

In the latest (eleventh) beta draft edition of the World Health Organization's International Statistical Classification of Diseases and Related Health Problems (ICD-11), gaming disorder was included for the very first time under the heading of 'Disorders due to substance use or addictive behaviours' (World Health Organization, 2018). This is a timely inclusion because online gaming is a rapidly growing and popular industry, as evidenced by the reported revenue of over $\$ 100$ billion (US) generated worldwide in 2017 (Batchelor, 2018). With increased use and popularity of online gaming, there is an increased risk of developing problematic online gaming and gaming disorder for a small minority of individuals (Naskar et al. 2016). This should be of concern to the general psychiatrist who may face the

*Address for correspondence: David Columb, Addiction Department, St John of God Hospital, Stillorgan, Co., Dublin, Ireland. (Email: david.columb@sjog.ie) increasing likelihood of individuals presenting with gaming problems in both adolescent and adult settings.

\section{Development of online gaming}

Online gaming (playing video games via the internet), although considered a relatively new phenomenon, has been in existence since the early 1970s. During this time, online gaming was primarily text based, such as the classic game Oregon Trail (1971), where players could type instructions to their characters in order to complete specific objectives. These games, while played over the internet, were single-player ventures and the players interacted between themselves and the game only. This changed with Maze War (1973) where, for the first time, online players could interact with each other within the game itself. The complexity and scope of online gaming grew over the years, with the development of Massively Multiplayer Online Role-Playing Games such as World of Warcraft in the early 2000s (GamesIndustry International, 2004). These games allowed millions of players across the globe to interact with one another through online gaming platforms. More recently, Multiplayer Online Battle Arena (MOBA) games (e.g. League of Legends) have seen a large increase in popularity, with video games like Fortnite hitting a peak of 3.4 million players concurrently online in August 2018 (Chalk, 2018). These online games can be accessed through a variety of means, such as through PC gaming (gaming via laptop or home personal computer), console gaming (dedicated gaming equipment such as PlayStation and Xbox consoles), and mobile 
gaming (via Android or Apple apps on smartphones or tablets).

There are many reasons why people engage in online gaming. These can be broken down into three overarching reasons for online gaming: for achievement, for social reasons, and for immersion in another world (Yee, 2006). Achievement focuses on looking to progress in games, accumulate in-game wealth and status, and challenge/compete with others (Yee, 2006). Social players look to work collaboratively with other players to achieve goals and to make friends, as well as to form and continue relationships with others (Yee, 2006). Players looking to immerse themselves in the game world enjoy the role-playing aspect of gaming. They engage in gaming in order to relax and to temporarily escape from real-life (Yee, 2006). Other authors have asserted more than three motivations for gaming such as Ballabio et al. (2017) who outlined seven motives (social, escape, competition, coping, skill development, fantasy, and recreation). Gamers can view gaming as a meaningful and purposeful activity and as a large part of their lives (Shi et al. 2019). However, a minority of people report negative experiences of online gaming and problematic gaming behaviours, such as a loss of control of time spent playing (Kuss \& Griffiths, 2012). Therefore, it is important for clinicians to be aware of the features of problematic gaming and gaming disorder given its upcoming inclusion in ICD-11 (World Health Organization, 2018).

\section{Gaming disorder}

It is important to note that, for the majority of players, video gaming is a harmless, pleasurable pursuit. Gaming can confer a number of cognitive, motivational, emotional, therapeutic, health, and social benefits (Granic et al. 2014). Gaming has been shown to improve spatial awareness (Uttal et al., 2013), problem-solving skills (Prensky, 2012), mood (Russoniello \& Parks, 2009), and can help people acquire important prosocial skills in games requiring cooperation with other people (Ewoldsen et al., 2012). Gaming has also been shown to have educational benefits (M. D. Griffiths, 2002) and to help children improve adherence to medical treatment (Kato et al. 2008).

However, as the popularity of gaming (especially online gaming) has increased, the levels of gaming addiction and its associated co-morbidities have become more prominent. The average prevalence of gaming addiction across countries is estimated at $4.7 \%$ (Feng et al. 2017). One of the main challenges facing clinicians is determining what differentiates healthy excessive interest in gaming from disordered gaming. In general, a healthy enthusiasm for video gaming has a positive effect on an individual's life, whereas an addiction to gaming has a negative effect on their life (M. D. Griffiths, 2010). In cases where gaming disorder may be suspected, it can be useful to apply the new criteria for gaming disorder as listed in the ICD-11. Here, gaming disorder is characterised by 'a pattern of persistent or recurrent gaming behaviour ("digital gaming" or "video-gaming"), which may be online (i.e., over the internet) or offline' (e.g. played on a gaming console) (World Health Organization, 2018). This is manifested by:

- Impaired control over gaming (e.g. onset, frequency, intensity, duration, termination, context)

- Increasing priority given to gaming to the extent that gaming takes precedence over other life interests and daily activities

- Continuation or escalation of gaming despite the occurrence of negative consequences.

The behaviour pattern needs to be of sufficient severity to result in significant clinical impairment in personal, family, social, educational, occupational, and/or other important areas of functioning. The gaming behaviour and other features are normally evident over a period of at least 12 months (World Health Organization, 2018). These features mirror those of 'Internet Gaming Disorder' (IGD) in DSM-5, where it is included in the section 'conditions for further study' (American Psychiatric Association, 2013).

Gaming disorder can present with a number of co-morbid psychopathologies. A recent systematic review reported the most common associations with gaming disorder are anxiety (92\%), depression (89\%), Attention Deficit Hyperactivity Disorder (ADHD)/ hyperactivity $(89 \%)$, and social phobia/obsessivecompulsive symptoms (75\%) (González-Bueso et al., 2018). However, the same review also noted that there is currently insufficient evidence to state whether or not gaming disorder is the cause or trigger of these psychopathologies (González-Bueso et al., 2018). It is therefore important to consider whether these symptoms are part of another disorder and/or if the excessive gameplay is being used as a coping strategy. Recent research from treatment-seeking adolescents with gaming disorders has shown various different aetiological pathways into problematic gaming (Torres-Rodriguez et al., 2018a, $2018 b$, 2019). For example, depressed individuals can be attracted to online gaming as a way of decreasing their dysphoria (Peng \& Liu, 2010). Other addictive behaviours can also be associated with problematic gaming. For instance, substance misuse has been associated with problematic gaming in adolescent boys, with nicotine, alcohol, and cannabis usage twice as high compared to their non-problematic gaming peers (Van Rooij et al., 2014). 
Gaming disorder is more prevalent in males than females, with the total prevalence of gaming disorder ranging from anywhere between $0.7 \%$ to $27.5 \%$, the disparity being most likely due to the methodological differences in each study including different sample populations, the use of different screening instruments, and different operationalisations of what constitutes problematic gaming (Mihara \& Higuchi, 2017). Time spent engaging in gaming is also a risk factor for developing gaming disorder (Mihara \& Higuchi, 2017). Gaming-disordered patients spent almost double the amount of time gaming per week (31 hours) compared to their non-disordered counterparts (19 hours) prior to onset of the gaming addiction in one longitudinal study (D. A. Gentile et al., 2011). However, the same author (D. Gentile, 2009) and others (e.g. Griffiths, 2010) have demonstrated that prolonged engagement in gaming does not necessarily mean the individual has a gaming disorder. Higher frequency of playing games and more years playing games have also been associated with the development of a gaming disorder (Mihara \& Higuchi, 2017). Furthermore, impulsivity and low self-control have been identified as important risk factors in developing a gaming disorder (Mihara \& Higuchi, 2017; Rho et al., 2017).

\section{Online gaming psychology}

Part of the success of contemporary online gaming is due to some of the psychological mechanisms (the so-called 'structural characteristics') employed throughout these games, such as the utilisation of 'near-misses'. The near-miss effect is 'a special kind of failure to reach a goal, one that comes close to being successful' (Reid, 1986). These near-misses have been shown to enhance reward pathways in the brain and motivate gambling behaviours (Clark et al. 2009) and are associated with addiction to slot machines (Mark Griffiths, 1991) as well as video games (D. King et al. 2010; M. D. Griffiths \& Nuyens, 2017). A study on the popular mobile game Candy Crush showed near-misses to be the most frustrating outcome (as compared to wins and losses) and the outcome that triggered the largest urge to continue to play the game (Larche et al. 2017). Online games can also use a variety of other reinforcement techniques, such as positive reinforcement, intermittent reinforcement, and punishment, in order to increase time spent playing the game (D. King et al., 2010).

Some specific strategies that can be employed in some online games are 'pay to skip' and 'grinding' (the performance of repetitive and tedious tasks typically as a solo endeavour or as part of team play). Players can be given the option of grinding to achieve a specific outcome (such as reaching another level), which could take hours of gameplay, or can pay to skip this process (Zagal et al. 2013). These online game strategies play into the increased impulsivity seen in gaming disordered patients and are a likely contributor to the relationship between gaming disorder and ADHD found in young adults (Yen et al., 2017).

\section{Micro-transactions in online gaming and the blurring between gambling and gaming}

Micro-transactions comprise the buying of virtual goods (such as 'loot boxes') or rewards that can be purchased for small payments within the game (Agarwal, 2017) and are a large factor in 'freemium' (free-to-play) games. Freemium games offer no cost to download and play the game but generally contain some form of micro-transaction or in-game commercial strategy (Evans, 2016). Profits from micro-transactions have been substantial, with one company reporting $\$ 4$ billion (US) in revenue from micro-transactions in 2017 (Makuch, 2018), just over half of its total revenue for the year.

Loot boxes are defined as 'in-game purchases consisting of a virtual container that awards players with items and modifications based on chance' (Rouse, 2018). Players do not know the value of what is inside the box or chest until they open it, and these have been described as 'virtual games of chance' (M. D. Griffiths, 2018). The reinforcement offered by these random boxes has been cited as a critical psychological ingredient of gaming addiction (M.D. Griffiths, 2009). Loot boxes have courted significant controversy over the past year. The UK Gambling Commission's position is that loot boxes are not a form of gambling because the items obtained from loot boxes do not have any real-life value outside the game (Gambling Commission, 2017). Others disagree, with the Belgian government declaring loot boxes to be a form of gambling and banning them from use in their country, citing loot boxes as encouraging children to gamble (MacDonald, 2018). Ireland have decided against labelling loot boxes as a form of gambling, with the Department of Justice stating that it 'does not have a role to regulate game developers on how their games work nor, in the offering of in-game purchases' (Irish Legal, 2018). A recent study found evidence for a link between the amount that video game players spent on loot boxes and the severity of problem gambling. In a large survey of 7422 gamers, the more money a person spent buying loot boxes, the more likely they were to be a problem gambler (Zendle \& Cairns, 2018). The article concluded that the gambling-like features of loot boxes could be responsible for problem-gambling severity, because the buying of other in-game items had no relationship with the level of problem gambling. 
In-game currencies are virtual currencies that can be used inside the game to purchase items such as customisable outfits or to obtain specific in-game advantages. The use of alternative currencies in these games has been described as a way to hide the true value of the purchases (Duverge, 2016). There is some evidence to suggest that the willingness to pay more money is heightened depending on the medium by which the customer is paying. For example, in one study, consumers were shown to spend more money using debit cards rather than cash payments, given the increased transparency of cash payments (Runnemark et al. 2015). The same finding has been found with players spending more money with chips compared to cash payments (Lapuz \& Griffiths, 2010). In addition, grinding to obtain in-game currency usually requires hours of gameplay to have currency in sufficient quantities to purchase certain items. This can encourage players to pay-to-skip in order to progress in the game and/ or unlock content at a faster rate (Hamari et al., 2017).

In-game currencies can also be used within some games to gamble. Popular games such as Grand Theft Auto: San Andreas and Red Dead Redemption allow the player to gamble using the in-game currency by playing casino games or playing poker (D. L. King et al. 2015). Although these are optional side games in their respective games, they still involve betting, chance, and financial rewards (in the form of currency that can be spent within the game) (D. L. King et al., 2015).

\section{Mobile gaming}

For many people, their first introduction to video gaming is through mobile gaming. Games such as Snake which were pre-programmed into Nokia phones in 1997 were immensely popular. Mobile games are now the largest growing gaming market and represent the largest share of the global games market, with more than $50 \%$ of the market share (Wijman, 2018). The majority of people with mobile phones engage in mobile gaming, with $72.3 \%$ of mobile users in the USA engaging in mobile gaming (WePC, 2019). Interestingly, compared to other forms of gaming, mobile gaming is more popular with females compared to males (Mobile Marketing Association, 2015). Candy Crush Saga, one of the most popular mobile social games, reports that $69 \%$ of people playing are female (Chen \& Leung, 2016). Most people engaging in mobile games play for fun, to be sociable (interacting with friends), for relaxation, to win, or to pass time (e.g. while on public transport) (Chen \& Leung, 2016).

Risk factors for mobile game addiction are similar to traditional video game addiction. Social isolation and a lack of self-control have been found to be important factors increasing risk of mobile game addiction
(Chen \& Leung, 2016). A major difference between mobile gaming and traditional gaming is the increased availability of these games given the ubiquity and availability of mobile phones (Engl \& Nacke, 2013). Often mobile games are designed for more casual players to easily enter and access the games (Engl \& Nacke, 2013) and utilised by people 'on-the-go', for example waiting for public transportation (Chen \& Leung, 2016). This increased accessibility has been seen as an important factor in other behavioural addictions such as gambling addiction (Columb \& O'Gara, 2017). However, a recent cross-cultural study found little evidence of gaming disorder among smartphone users who played mobile games (Lopez-Fernandez et al., 2018).

\section{Esports}

Esports are 'competitive (pro and amateur) video gaming that is often coordinated by different leagues, ladders, and tournaments, and where players customarily belong to teams or other "sporting" organizations who are sponsored by various business organizations' (Hamari \& Sjöblom, 2017). Viewers can watch professional players play against each other in a variety of games such as MOBA games (League of Legends) or sports games (FIFA 19). The popularity of esports is growing exponentially, with a worldwide audience size of 380 million in 2018 (Fuller, 2018). The popularity of esports is aided by live video-streaming platforms such as Twitch - a live video-streaming platform focused on video game live-streaming as well as live-streaming of other content such as sport, music, and other creative content (Stephenson, 2018). Esports, via Twitch, stream to 100 million live viewers per month watching for an average of 106 minutes per day (MD Griffiths, 2017). On 13 May, 2018, Ireland hosted the Three Ireland EStars League, an 8-week esports competition considered the first major esports tournament in Ireland (Cocking, 2018). There is a large gambling element associated with esports (Bányai, Griffiths, Király, \& Demetrovics), and it is estimated that gambling on esports will reach $\$ 10$ billion US dollars by 2020 (MD Griffiths, 2017).

\section{Treatment and management of gaming disorder}

Even though gaming disorder is only just beginning to come to the fore as a recognised addiction (Saunders et al., 2017), there are currently very few treatment options existing in Ireland. Some private specialist outpatient services and residential addiction centres offer treatment for gaming addiction in Ireland, but there are no dedicated services within the Irish mental health system. Irish child and adolescent psychiatrists are reporting increasing presentations to their clinics of parents seeking help for their child's gaming addiction 
(Kelleher, 2019). More specialist units will be required in the future as improved awareness and continued exposure to online gaming is likely to see an increase in presentations for gaming disorder.

In relation to specific treatment efficacy, there is a need for further research in this area. A systematic review of treatments for gaming disorder showed that there is a need for more evidence-based research (D. L. King et al., 2017) although some recent studies have shown success among adolescents with IGD in Spain (Torres-Rodríguez et al. 2018). CBT has a larger base of positive evidence compared to other treatment modalities, including medication (D. L. King et al., 2017). CBT has also been shown to improve symptoms of gaming disorder and co-morbid depression. However, these gains tend to be short term and further support post-treatment completion is likely required (Stevens et al. 2018).

There is no current consensus on the utility of medication in the treatment of gaming disorder. Bupropion has shown some promise (Han et al. 2010) but requires further independent double-blind studies (D. L. King et al. 2017). Escitalopram was found to be beneficial in the treatment of gaming disorder in a randomised control trial alongside bupropion (with bupropion showing greater efficacy in relation to attention and impulsivity than escitalopram in the same trial) (Song et al. 2016). ADHD medications (atomoxetine, methylphenidate) have shown reductions in gaming disorder symptoms over a 12-week period in adolescents (Park et al. 2016). Further double-blind RCTs are required for these medications before definitive conclusions can be made on their efficacy in gaming disorder treatment (Zajac et al. 2017).

\section{Conclusion}

Given the rise of online gaming and the recognition of gaming disorder as an addictive behaviour, there is a need for increased recognition of this disorder within the Irish healthcare system. Further research is required into efficacious treatment programmes for gaming disorder. Referral pathways need to be established to manage the current presentations of gaming disorder to our services with the goal of providing the most up-to-date and effective treatment options for these patients.

\section{Financial support}

No financial support was provided for this work.

\section{Conflicts of interest}

David Columb has no conflicts of interest to disclose. Mark D. Griffiths (MDG)'s university received funding from Norsk Tipping (the gambling operator owned by the Norwegian Government) for this research. MDG received funding for a number of research projects in the area of gambling education for young people, social responsibility in gambling, and gambling treatment from Gamble Aware (formerly, the Responsibility in Gambling Trust), a charitable body that funds its research program based on donations from the gambling industry. MDG also undertakes consultancy for various gaming companies in the area of social responsibility in gambling. Colin O'Gara has no conflicts of interest to disclose.

\section{Ethical standards}

The authors assert that all procedures contributing to this work comply with the ethical standards of the relevant national and institutional committee on human experimentation with the Helsinki Declaration of 1975, as revised in 2008 .

\section{References}

Agarwal P (2017). Economics of Microtransactions in Video Games. Retrieved from https:/ /www.intelligent economist.com/economics-of-microtransactions/

American Psychiatric Association (2013). Diagnostic and Statistical Manual of Mental Disorders (DSM-5®). American Psychiatric Association Publishing: Arlington, VA.

Ballabio M, Griffiths MD, Urbán R, Quartiroli A, Demetrovics Z, Király O (2017) Do gaming motives mediate between psychiatric symptoms and problematic gaming? An empirical survey study. Addiction Research $\mathcal{E}$ Theory, 25, 397-408.

Bányai F, Griffiths MD, Király O, Demetrovics Z (2019) The psychology of esports: a systematic literature review. Journal of Gambling Studies, 35, 351-365.

Batchelor J (2018). Games industry generated $\$ 108.4 \mathrm{bn}$ in revenues in 2017. Retrieved from https:/ /www. gamesindustry.biz/articles/2018-01-31-games-industrygenerated-usd108-4bn-in-revenues-in-2017

Chalk A (2018). Fortnite passes PUBG with 3.4 million concurrent players. Retrieved from https: / www. pcgamer.com/fortnite-passes-pubg-with-34-millionconcurrent-players /

Chen C, Leung L (2016). Are you addicted to Candy Crush Saga? An exploratory study linking psychological factors to mobile social game addiction. Telematics and Informatics 33, 1155-1166.

Clark L, Lawrence AJ, Astley-Jones F, Gray N (2009). Gambling near-misses enhance motivation to gamble and recruit win-related brain circuitry. Neuron 61, 481-490.

Cocking S (2018). Will 2018 be the year that Ireland finally embraces eSports? Retrieved from https://irishtechnews.ie/ will-2018-be-the-year-that-ireland-finally-embraces-esports/

Columb D, O'Gara C (2018). A national survey of online gambling behaviours. Irish Journal of Psychological Medicine 35, 311-319.

Duverge G (2016). Insert More Coins: The Psychology Behind Microtransactions. Retrieved from https://www.tuw.edu/ content/psychology/psychology-behind-microtransactions/ 
Engl S, Nacke LE (2013). Contextual influences on mobile player experience-A game user experience model. Entertainment Computing 4, 83-91.

Evans E (2016). The economics of free: Freemium games, branding and the impatience economy. Convergence 22, 563-580.

Ewoldsen DR, Eno CA, Okdie BM, Velez JA, Guadagno RE, DeCoster J (2012). Effect of playing violent video games cooperatively or competitively on subsequent cooperative behavior. Cyberpsychology, Behavior, and Social Networking, 15(5), 277-280.

Feng W, Ramo D, Chan S, Bourgeois J (2017). Internet gaming disorder: trends in prevalence 1998-2016. Addictive behaviors 75, 17.

Fuller S (2018). eSports market - Statistics \& Facts. Retrieved from https://www.statista.com/topics/3121/ esports-market/

Gambling Commission (2017). Loot boxes within video games. Retrieved from https://www. gamblingcommission.gov.uk/news-action-and-statistics / news / 2017/Loot-boxes-within-video-games.aspx

GamesIndustry International (2004). Blizzard Entertainment Announces World Of Warcraft "Street Date". Retrieved from https://www.gamesindustry.biz/articles/blizzardentertainment-announces-world-of-warcraft-street-datenovember-23-2004

Gentile D (2009). Pathological video-game use among youth ages 8 to 18: a national study. Psychological Science 20, 594-602.

Gentile DA, Choo H, Liau A, Sim T, Li D, Fung D, Khoo A (2011). Pathological video game use among youths: a two-year longitudinal study. Pediatrics 127, e319-e329.

González-Bueso V, Santamaría J, Fernández D, Merino L, Montero E, Ribas J (2018). Association between internet gaming disorder or pathological video-game use and comorbid psychopathology: a comprehensive review. International Journal of Environmental Research And Public Health 15, 668.

Granic I, Lobel A, Engels RC (2014). The benefits of playing video games. American Psychologist 69, 66.

Grant JE, Potenza MN, Weinstein A, Gorelick DA (2010). Introduction to behavioral addictions. The American Journal of Drug and Alcohol Abuse 36, 233-241. doi:10. 3109/00952990.2010.491884

Griffiths M (1991). Psychobiology of the near-miss in fruit machine gambling. The Journal of Psychology 125, 347-357.

Griffiths MD (2002). The educational benefits of videogames. Education and Health 20, 47-51.

Griffiths M (2009). Online computer gaming: advice for parents and teachers. Education and Health 27, 3-6.

Griffiths MD (2010). The role of context in online gaming excess and addiction: some case study evidence. International Journal of Mental Health and Addiction 8, 119-125.

Griffiths M (2017). The psychosocial impact of professional gambling, professional video gaming \& eSports. Casino $\mathcal{E}$ Gaming International 28, 59-63.

Griffiths MD (2018). Is the buying of loot boxes in video games a form of gambling or gaming? Gaming Law Review $22,52-54$.
Griffiths MD, Nuyens F (2017). An overview of structural characteristics in problematic video game playing. Current Addiction Reports 4, 272-283.

Hamari J, Sjöblom M (2017). What is eSports and why do people watch it? Internet research 27, 211-232.

Hamari J, Alha K, Järvelä S, Kivikangas JM, Koivisto J, Paavilainen J (2017). Why do players buy in-game content? An empirical study on concrete purchase motivations. Computers in Human Behavior 68 538-546.

Han DH, Hwang JW, Renshaw PF (2010). Bupropion sustained release treatment decreases craving for video games and cue-induced brain activity in patients with Internet video game addiction. Experimental and Clinical Psychopharmacology 18, 297-304.

Irish Legal (2018). Government shies away from crackdown on 'loot box' games. Retrieved from https:/ /www. irishlegal.com/article/government-shies-away-fromcrackdown-on-loot-box-games

Kato PM, Cole SW, Bradlyn AS, Pollock BH (2008). A video game improves behavioral outcomes in adolescents and young adults with cancer: a randomized trial. Pediatrics 122, e305-e317.

Kelleher L (2019, February 17). Irish psychiatrists treating children for 'gaming disorder. Irish Independent. Retrieved from https://www.independent.ie/business/technology/ tech-gaming/irish-psychiatrists-treating-children-forgaming-disorder-37823351.html

King D, Delfabbro P, Griffiths M (2010). Video game structural characteristics: a new psychological taxonomy. International Journal of Mental Health and Addiction 8, 90-106.

King DL, Delfabbro PH, Wu AM, Doh YY, Kuss DJ, Pallesen S, ... Sakuma H (2017). Treatment of internet gaming disorder: an international systematic review and CONSORT evaluation. Clinical Psychology Review 54, 123-133.

King DL, Gainsbury SM, Delfabbro PH, Hing N, Abarbanel B (2015). Distinguishing between gaming and gambling activities in addiction research. Journal of Behavioral Addictions 4, 215-220.

Kuss DJ, Griffiths MD (2012). Internet gaming addiction: a systematic review of empirical research. International Journal of Mental Health and Addiction 10, 278-296.

Lapuz J, Griffiths MD (2010). The role of chips in poker gambling: an empirical pilot study. Gambling Research: Journal of the National Association for Gambling Studies (Australia) 22, 34.

Larche CJ, Musielak N, Dixon MJ (2017). The Candy Crush Sweet Tooth: how 'near-misses' in Candy Crush increase frustration, and the urge to continue gameplay. Journal of Gambling Studies 33, 599-615.

Lopez-Fernandez O, Männikkö N, Kääriäinen $M$, Griffiths MD, Kuss DJ (2018). Mobile gaming does not predict smartphone dependence: A cross-cultural study between Belgium and Finland. Journal of Behavioral Addictions 7, 88-99.

MacDonald K (2018). Belgium is right to class video game loot boxes as child gambling. Retrieved from https:/ / www.theguardian.com/games/2018/apr/26/belgium-isright-to-legislate-against-video-game-loot-boxes 
Makuch E (2018). Activision Blizzard made $\$ 4$ billion on microtransactions last year. Retrieved from https: / /www. gamespot.com/articles/activision-blizzard-made-4billion-on-microtransac/1100-6456669/

Mihara S, Higuchi S (2017). Cross-sectional and longitudinal epidemiological studies of Internet gaming disorder: a systematic review of the literature. Psychiatry and Clinical Neurosciences 71, 425-444.

Mobile Marketing Association (2015). Myth busting: mobile gaming demographics. Retrieved from https://www. mmaglobal.com/research/myth-busting-mobile-gamingdemographics

Naskar S, Victor R, NathK, Sengupta C (2016). “One level more:" a narrative review on internet gaming disorder. Industrial psychiatry journal 25, 145.

Park JH, Lee YS, Sohn JH, Han DH (2016). Effectiveness of atomoxetine and methylphenidate for problematic online gaming in adolescents with attention deficit hyperactivity disorder. Human Psychopharmacology: Clinical and Experimental 31, 427-432.

Peng W, Liu M (2010). Online gaming dependency: a preliminary study in China. Cyberpsychology, Behavior, and Social Networking 13, 329-333.

Prensky MR (2012). From Digital Natives to Digital Wisdom: Hopeful Essays for 21st Century Learning. Thousand Oaks: Corwin Press.

Reid R (1986). The psychology of the near miss. Journal of Gambling Behavior 2, 32-39.

Rho M, Lee H, Lee T-H, Cho H, Jung D, Kim D-J, Choi I (2017). Risk factors for internet gaming disorder: psychological factors and internet gaming characteristics. International Journal of Environmental Research and Public Health 15, 40.

Rouse M (2018). Loot box. Retrieved from https: / / whatis. techtarget.com/definition/loot-box

Runnemark E, Hedman J, Xiao X (2015). Do consumers pay more using debit cards than cash? Electronic Commerce Research and Applications 14, 285-291.

Russoniello CV, Parks JM (2009). EEG, HRV and Psychological Correlates while Playing Bejeweled II: a randomized controlled study. Studies in Health Technology And Informatics, 144, 189-192

Saunders JB, Hao W, Long J, King DL, Mann K, FauthBühler M, .. Chung T (2017). Gaming disorder: its delineation as an important condition for diagnosis, management, and prevention. Journal of Behavioral Addictions 6, 271-279.

Shi J, Renwick R, Turner NE, Kirsh B (2019). Understanding the lives of problem gamers: the meaning, purpose, and influences of video gaming. Computers in Human Behavior 97 291-303.

Song J, Park JH, Han DH, Roh S, Son JH, Choi TY, ... Lee YS (2016). Comparative study of the effects of bupropion and escitalopram on Internet gaming disorder. Psychiatry and Clinical Neurosciences 70, 527-535.

Stephenson B (2018). Twitch: everything you need to know. Retrieved from https://www.lifewire.com/what-istwitch-4143337
Stevens MW, King DL, Dorstyn D, Delfabbro PH (2018). Cognitive-behavioral therapy for Internet gaming disorder: a systematic review and meta-analysis. Clinical Psychology \& Psychotherapy 26, 191-203.

Torres-Rodríguez A, Griffiths MD, Carbonell X (2018a). The treatment of internet gaming disorder: a brief overview of the PIPATIC program. International Journal of Mental Health and Addiction 16, 1000-1015.

Torres-Rodríguez A, Griffiths MD, Carbonell X, Oberst U (2018b). Psychological characteristics of an adolescent clinical sample with Internet Gaming Disorder. Journal of Behavioral Addictions 7, 707-718.

Torres-Rodríguez A, Griffiths MD, Carbonell X, Oberst U (2018c). Treatment effectiveness of a specialized psychotherapy program for Internet Gaming Disorder. Journal of Behavioral Addictions 7, 939-952.

Torres-Rodríguez A, Griffiths MD, Carbonell X, FarriolsHernando N, Torres-Jimenez E (2019). Internet gaming disorder treatment: A case study evaluation of four adolescent problematic gamers. International Journal of Mental Health and Addiction 17, 1-12.

Uttal DH, Meadow NG, Tipton E, Hand LL, Alden AR, Warren C, Newcombe NS (2013). The malleability of spatial skills: a meta-analysis of training studies. Psychological Bulletin 139, 352.

Van Rooij AJ, Kuss DJ, Griffiths MD, Shorter GW, Schoenmakers TM, Van De Mheen D (2014). The (co-) occurrence of problematic video gaming, substance use, and psychosocial problems in adolescents. Journal of Behavioral Addictions 3, 157-165.

WePC (2019). 2019 Video Game Industry Statistics, Trends \& Data. Retrieved from https://www.wepc.com/news/ video-game-statistics /

Wijman T (2018). Mobile revenues account for more than $50 \%$ of the Global Games Market as it reaches \$137.9 billion in 2018. Retrieved from https:/ / newzoo.com/

World Health Organization (2018). International statistical classification of diseases and related health problems (11th Revision) - 6C51 Gaming Disorder. Retrieved from https://icd.who.int/browse11/l-m/en\#/http://id.who. int/icd/entity/1448597234

Yee N (2006). Motivations for play in online games. CyberPsychology \& Behavior 9, 772-775.

Yen J-Y, Liu T-L, Wang P-W, Chen C-S, Yen C-F, Ko C-H (2017). Association between Internet gaming disorder and adult attention deficit and hyperactivity disorder and their correlates: Impulsivity and hostility. Addictive Behaviors 64, 308-313.

Zagal JP, Björk S, Lewis C (2013). Dark patterns in the design of games. In Foundations of Digital Games. Retrieved April 12, 2019, from http:/ / www.diva-portal.org/smash/get/diva2: 1043332/FULLTEXT01.pdf

Zajac K, Ginley MK, Chang R, Petry NM (2017). Treatments for Internet gaming disorder and Internet addiction: a systematic review. Psychology of Addictive Behaviors, 31, 979.

Zendle D, Cairns P (2018). Video game loot boxes are linked to problem gambling: Results of a large-scale survey. PLoS One, 13, e0206767. 